\title{
MRI use with artificial erection in cases of painful erections
}

\author{
Marc A. Lucky, MBChB, FRCS(Urol); Luke A. McGuinness, BMBS, MRCS; \\ Michael S. Floyd Jr, MCh, FRCS(Urol); Nigel J. Parr, MD, FRCSE(Urol)
}

Department of Urology, Arrowe Park Hospital, Arrowe Park Road, Wirral, Merseyside, CH49 5PE, United Kingdom

Cite as: Can Urol Assoc J 2014;8(11-12):394.

http://dx.doi.org/10.5489/cuaj.2489

Published online December 15, 2014.

W e read with great interest the recent case report by Barber and Domes in CUAJ describing a case of painful erections caused by epithelioid haemangioma, a rare but benign lesion. ${ }^{1}$ They highlight the use of penile magnetic resonance imaging (MRI) with artificially induced erection in aiding diagnosis of a penile lesion that was unapparent on clinical examination.

Just prior to their article publication, we described a similar case of epithelioid hemangioma with painful erections and sleep deprivation. ${ }^{2}$ Initially thought to be painful Peyronie's disease, our case also required the use of penile MRI following intracavernosal alprostadil injection for more definitive diagnosis. Barber and Domes emphasize that such a lesion may not have been seen on conventional MRI and in our report this was indeed shown to be the case. While this technique has previously been described in staging penile cancer and investigation of erectile dysfunction and Peyronie's disease, ${ }^{3-5}$ both these case reports draw attention to the use of MRI with artificial erection induction in cases of painful erections.

Evidently this raises the question of how many painful erections are misdiagnosed as Peyronie's disease on the basis of clinical history even with the use of conventional MRI.
We hope both these cases illustrate that the consideration of MRI with artificial erection induction can be worthwhile.

Competing interests: Authors declare no competing financial or personal interests.

\section{References}

1. Barber E, Domes T. Painful erections secondary to rare epithelioid hemangioma of the penis. Can Urol Assoc J 2014;8:e647-9. http://dx.doi.org/10.5489/cuaj.1833

2. Lucky M, McGuinness L, Floyd MS Jr, et al. Epithelioid haemangioma: A rare cause of painful erections and sleep deprivation. Int Urol Nephrol 2014;46:1747-50. http://dx.doi.org/10.1007/ s1 1255-014-0705-2

3. Scardino E, Villa G, Bonomo G, et al. Magnetic resonance imaging combined with artificial erection for local staging of penile cancer. Urology 2004;63:1158-62. http://dx.doi.org/10.1016/i.urology.2004.01.008

4. Kurbatov D, Kuznetsky Y, Kitaev S, et al. Magnetic resonance imaging as a potential tool for objective visualization of venous leakage in patients with veno-occlusive erectile dysfunction. Int J Impot Res 2008;20:192-8. http://dx.doi.org/10.1038/ si.jiir.3901607

5. Hauck E, Hackstein N, Vosshenrich R, et al. Diagnostic value of magnetic resonance imaging in Peyronie's disease-a comparison both with palpation and ultrasound in the evaluation of plaque formation. Eur Urol 2003;43:293-9. http://dx.doi.org/10.1016/ S0302-2838(03)00003-4

Correspondence: Mr. Luke A. McGuinness, Department of Urology, Arrowe Park Hospital, Arrowe Park Road Wirral, Merseyside, CH49 5PE United Kingdom; luke.meguinness@doctors.org.uk
CUAJ Letters is an open forum to discuss papers published in CUAJ. Letters are published at the discretion of the editors, and are subject to abridgement and editing for style and content. Letters can be sent to the Editor at journal@cua.org.

\section{Author response: MRI use with artificial erection in cases of painful erections}

\section{Evan Barber, MD;* Trustin Domes, $M D, M E d, F_{C S C}^{+}$}

*College of Medicine, University of Saskatchewan, Saskatoon, SK; 'Saskatoon Health Region, Saskatoon, SK

Cite as: Can Urol Assoc J 2014;8(11-12):394-5.

http://dx.doi.org/10.5489/cuaj.2576

Published online December 15, 2014.

T hank you for your letter ${ }^{1}$ regarding our recent case report. ${ }^{2}$ We were very interested to read your article, ${ }^{3}$ which was published following our submission. As you point out, our cases are remarkably similar in terms of patient presentation, pathology and clinical approach, including the use of penile magnetic resonance imaging (MRI) with pharmacologically induced erection. We performed penile MRI in the symptomatic erect state only, and therefore were unable to comment on whether flaccid imaging would have been sufficient for this particular lesion. In your case, MRI in the flaccid state did not show the 